2018

\title{
Polycrystalline Silicon Solar Module Power Max
}

Jaynil Patel

University of South Florida

Advisors:

Arcadii Grinshpan, Mathematics and Statistics

William May, Solar Advantage Inc.

Problem Suggested By: William May

Follow this and additional works at: https://digitalcommons.usf.edu/ujmm

Part of the Mathematics Commons

UJMM is an open access journal, free to authors and readers, and relies on your support: Donate Now

\section{Recommended Citation}

Patel, Jaynil (2018) "Polycrystalline Silicon Solar Module Power Max," Undergraduate Journal of Mathematical Modeling: One + Two: Vol. 8: Iss. 2, Article 4.

DOI: http://doi.org/10.5038/2326-3652.8.2.4891

Available at: https://digitalcommons.usf.edu/ujmm/vol8/iss2/4 


\title{
Polycrystalline Silicon Solar Module Power Max
}

\begin{abstract}
In recent years solar energy has started to make its impact in the sunshine state. The solar panels are made up of photovoltaic cells, which convert the sun's rays into electricity. One of the ways to improve solar panel efficiency is to increase the power output of a solar collector. The maximum power is calculated by determining the maximum power for voltage and the current. This is done by adding the maximum values for the equation for power and then using differentiation. After the maximum values are found for each hour of the day from sunset to noon, each individual quantity of maximum voltage, current, and power is graphed as a function of the time of day. To make the solar panel work at its greatest power a controller has been used to maximize its efficiency.
\end{abstract}

\section{Keywords}

solar energy, solar panel efficiency, solar collector, transcendental equation

\section{Creative Commons License}

(c) (i) $\Theta$

This work is licensed under a Creative Commons Attribution-Noncommercial-Share Alike 4.0 License. 


\section{PROBLEM STATEMENT}

We need to determine the maximal power, current and voltage generated by a polycrystalline silicon solar module within a certain time frame. The relationship between current and voltage for a polycrystalline silicon solar module is represented by the equation: $I=I_{P V}-I_{0}\left(e^{b v}-1\right)$, where $I_{P V}$ is the current intensity for the solar module, $I_{0}$ and $b$ are constants $\left(I_{0}=5.22 \times 10^{-5}\right.$ amps, $\left.b=0.5\right)$. The photovoltaic current variable depends on the amount of incoming solar radiation. For the purpose of this project we will consider a polycrystalline silicon solar model from the Solar Advantage Company. For this kind of solar panel, we can represent $I_{P V}$ by: $I_{P V}=3.57 \sin [\pi(t-6) / 12]$, where $t$ is the hour of the day ( $t=6$ represents sunrise and $t=12$ represents noon), and $I_{P V}$ is given in amps. For the purpose of this project a controller has been used to make the solar panel work at its greatest power. We can obtain power $P$, from current intensity $I$ and voltage $V$ using the equation: $P=I V$.

\section{MOTIVATION}

Global warming has become a central issue in recent years. While complete understanding of it is still the matter of debate and research, it has also become clear that the further development of renewable energy production will play a fundamental role in the future. Solar energy can surely be considered as one of the main green energy sources.

Because nonrenewable resources are not infinite most experts believe they will cease to exist. According to Carty, who is an ecologist at ADI Energy Research Company, the natural gas supply will run out within the next 35 years and within 70 years the world's 
current oil reserves will be gone [Carty]. If the current rate of consumption of oil continues, "the supply is predicted to run out within the next 14 years" [Carty]. The U.S. places second in the world in annual carbon dioxide emissions at $17.9 \%$ in the world's total carbon dioxide emission, right behind China [Top 10 Benefits]. Turning to renewable energy sources, like solar energy, will help pave the way towards an environmentally friendly 21 st century.

According to Damaschke, a solar energy researcher from the University of Minnesota, even today's most efficient solar cells convert just over twenty percent of the sun rays to electricity. The primary disadvantage of solar power is that it does not produce any output during night. The solar panel energy output is maximized when the panel is directly facing the sun. Consequently, turning the solar panels as the sun is moving from east to west might significantly increase the efficiency of a solar panel. Ever since the 80's scientists and engineers have been modifying solar panels to increase their efficiency by reducing the size of solar cells or redesigning the solar models to increase power output.

The purpose of this project is to see the maximum power, current, and voltage obtained by a polycrystalline silicon solar module from sunrise to noon.

\section{MATHEMATICAL DESCRIPTION AND SOLUTION APPROACH}

The first equation shows the relationship between voltage and current for this module given by:

$$
I=I_{P V}-I_{0}\left(e^{b v}-1\right)
$$


In equation (1) IPv is known as the photovoltaic current that can be represented by the equation:

$$
I_{P V}=3.57 \sin [\pi(t-6) / 12]
$$

The relationship between current to voltage and power is given by the equation:

$$
P=I V
$$

where $\mathrm{P}$ is power, $\mathrm{V}$ is voltage and I indicates the current intensity.

Now that these equations have been established the first thing is to determine $I_{P V}$ at each hour from $t=6$ to $t=12$, using equation (2). Next, we calculate the power of max voltage by substituting equation (1) into equation (3).

$$
P=I V=\left(I_{P V}-I_{0}\left(e^{b v}-1\right)\right) V
$$

Now we can identify the max power with respect to voltage using the derivative of $P$ with respect to $V$, and setting it to be zero:

$\frac{d P}{d V}=I_{P V}-I_{0}\left(e^{b V}-1\right)-\left(I_{0} b e^{b V}\right) V=I_{P V}+I_{0}-I_{0} e^{b V}(1+b V)$,

$$
I_{P V}+I_{0}-I_{0} e^{b V}(1+b V)=0
$$

Using $b=1 / 2, I_{0}=5.22 \times 10^{-5}$ amps, and using equations (2) and (6), we get:

$$
\left(5.22 \times 10^{-5}\right)\left[e^{\frac{V}{2}}(1+(V / 2))-1\right]=3.57 \sin \left[\frac{\pi(t-6)}{12}\right]
$$

Since $\sin [\pi(t-6) / 12]$ is increasing between $t=6$ to $t=12$, it follows that $e^{V / 2}(1+(V / 2))-1$ as a 
function of $t$ increases on the interval $6 \leq t \leq 12$. This shows that $V(t)$ which is a solution to the transcendental equation (7) increases as $t$ increases on the considered interval. The $\max V$ happens when $t$ is at the $\max$ of 12 . The power is at $\max$ when $\mathrm{t}=12: \mathrm{V}_{\mathrm{Max}}=17.69$. Using equations (1), (2), and (3) to compute for the max power allowed, we have (8):

$$
P_{\max }=\left\{3.57-I_{0}\left(e^{V \max / 2}-1\right)\right\} V_{\max } \approx 56.75 \mathrm{~W}
$$

Table 1: Correlation between Time and Voltage

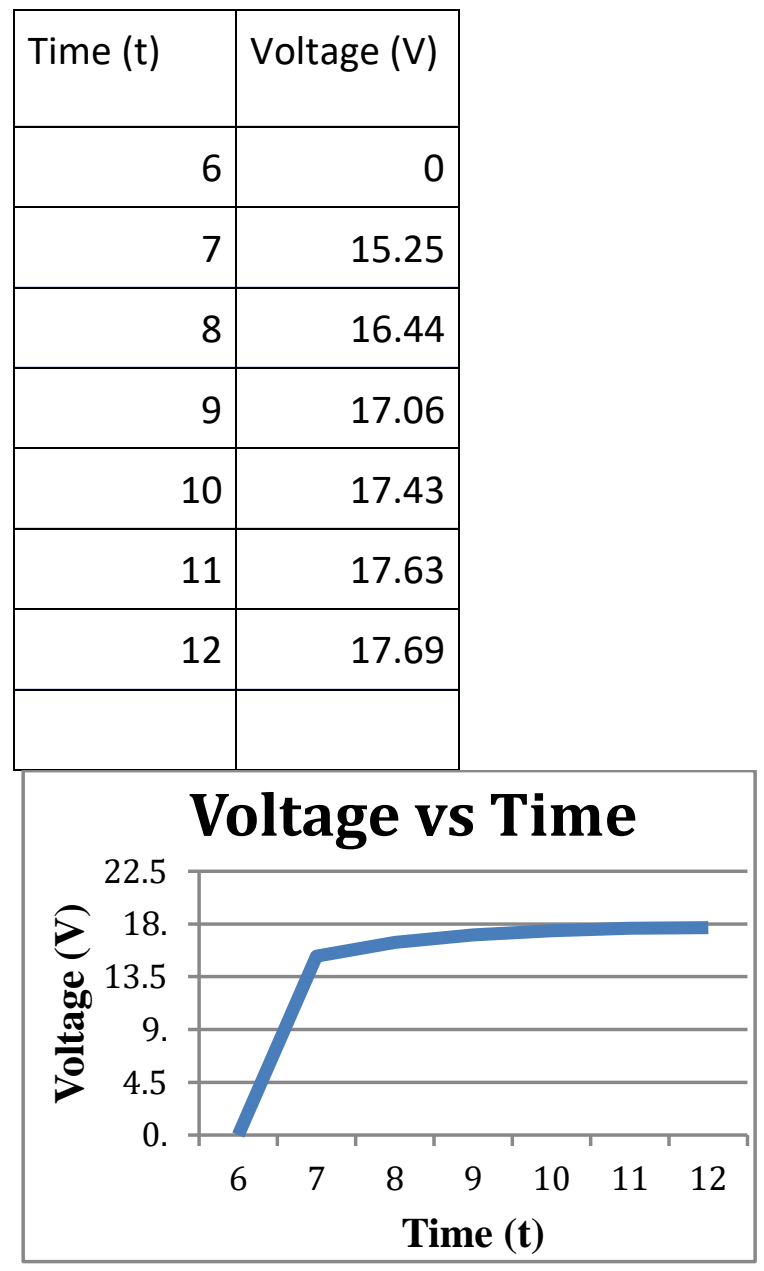

Figure 1: Graph of how voltage in the solar panel correlates as time increases. 


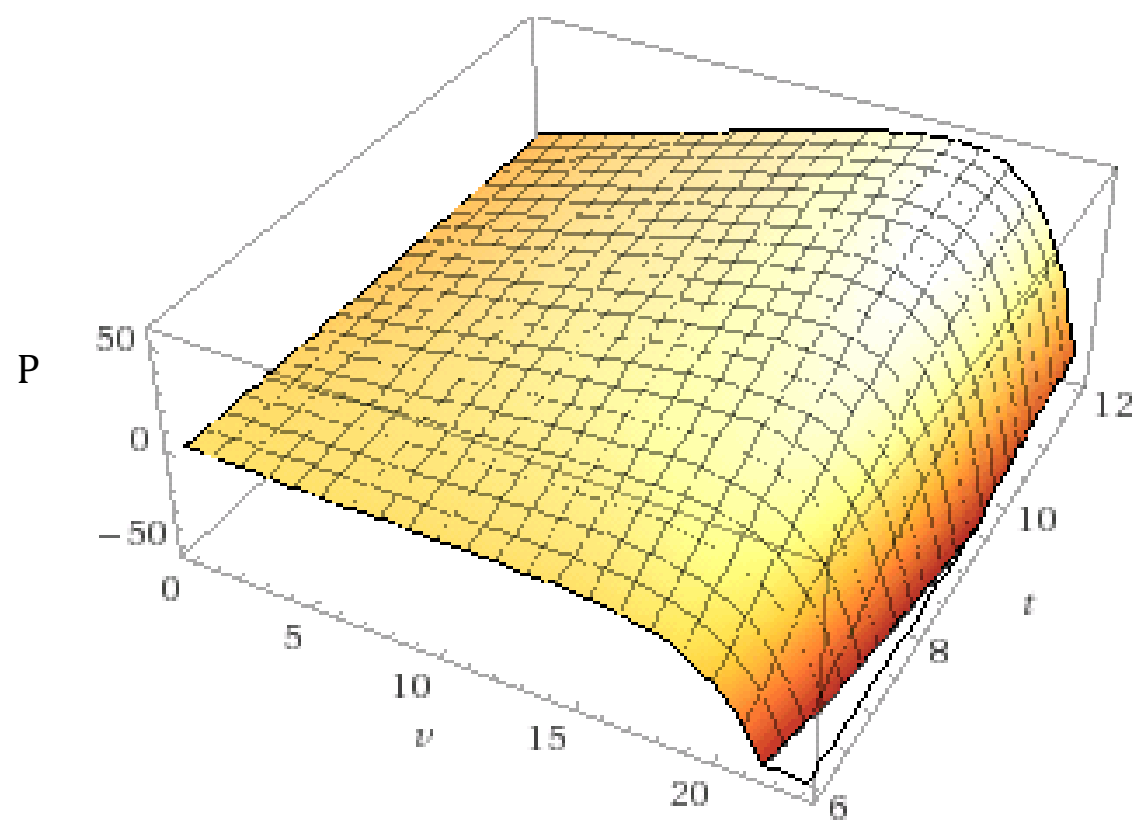

Figure 2: 3D model of how voltage in the solar panel correlates as time increases.

\section{DISCUSSION}

The first graph shows that as the time increases so does the voltage. The second graph shows that as time increases so does the power. The graph and table illustrate a trend with the voltage of max power and the current of maximum power. The results were not surprising since the highest input of photons of light from the sun is reached at noon.

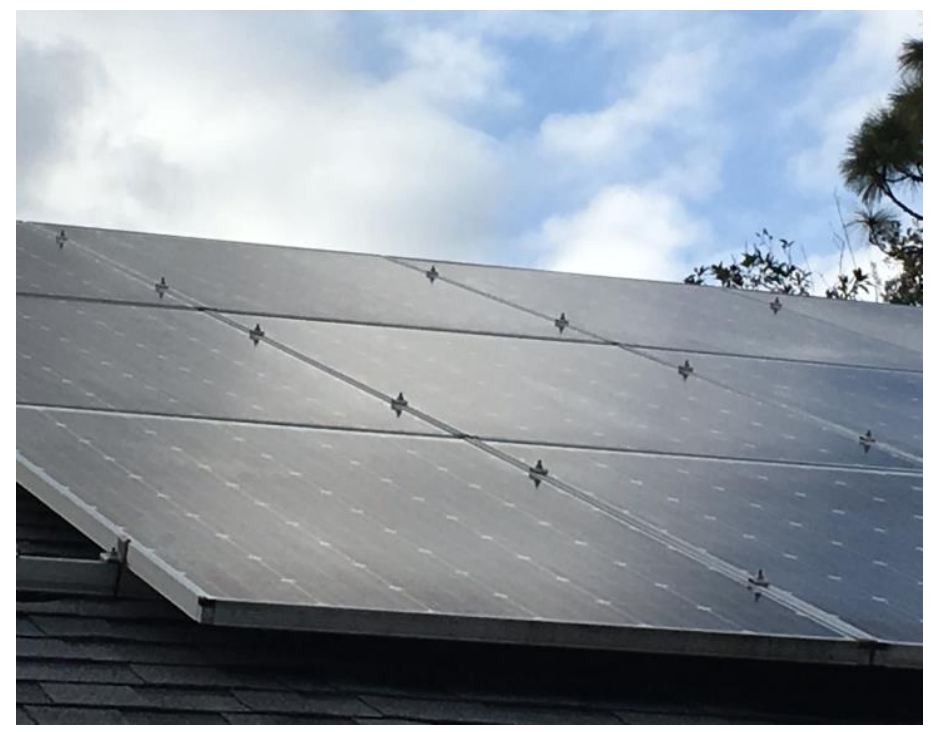

The amount of photons increases until noon and then goes back down at sunset. The results past noon have been omitted since as the sun goes down less photons are collected by the solar panel. Our results show both a 
weakness and strength of using solar energy as an alternative power source. Solar energy is a free power source but it is only limited to a certain time of the day. One of the things that engineers and scientists in the field of solar energy need to figure out is how to build a big enough battery pack to power a house throughout the whole day. Currently solar panels only convert about twenty percent of sun rays. This limitation is a strong indicator that much work can still be done in this relatively new sector.

\section{CONCLUSION AND RECOMMENDATIONS}

The objective of the project was to determine the maximal power, current and voltage generated by a polycrystalline silicon solar module within a certain time frame. We have used the notion of derivate of a function to determine a maximum value. The framework for the polycrystalline silicon solar module was used to help determine the relationship of time, current, power, and voltage. Creating more efficient photovoltaic cells per surface can help achieve the goal of converting more of the sun rays into energy.

One recommendation we have for someone who is planning to do a similar project is to do a test on multiple days to get an average result. The day we did our test was a fairly cloudy one so the solar panel was unable to get the max amount of the rays. Lastly, we would recommend to do a test on more than one type of solar panel. 


\section{NOMENCLATURE}

\begin{tabular}{|l|l|l|}
\hline Symbol & Description & Units \\
\hline$I$ & Current & Amps \\
\hline$P$ & Power & Watts \\
\hline$V$ & Voltage & Volts \\
\hline
\end{tabular}

\section{REFERENCES}

"Advantages and Disadvantages of Solar Energy | GreenMatch.co.uk." Advantages and Disadvantages of Solar Energy GreenMatch.co.uk. GreenMatch, 28 Aug. 2014. Web. 31 Mar. 2016.

Carty, Sue Lynn. "Non Renewable Resources." LoveToKnow. LTK, n.d. Web. 15 Apr. 2016.

Dhar, Michael. "How Do Solar Panels Work?" LiveScience. Purch, 13 Dec. 2013. Web. 08 Dec. 2016. <http://www.livescience.com/41995-how-do-solar-panels-work.html>.

Stewart, James, and Troy Day. Biocalculus: Calculus, Probability, and Statistics for the Life Sciences. Boston, MA, USA: Cengage Learning, 2016. Print.

"Top 10 Benefits of Going Solar - Energy Informative." Energy Informative. N.p., n.d. Web. 1 Mar. 2016. 